\title{
Simultaneous pancreas-kidney transplantation: Early complications and long-term outcomes - a single-centre experience
}

Natalia Vidal Crespo ${ }^{1}$; Pedro López Cubillana ${ }^{1}$; Pedro A. López González ${ }^{1}$; Cristóbal Moreno Alarcón'; Javier Rull Hernández ; Laura Aznar Martínez; Alicia López Abad ${ }^{1}$; Juan C. Fernández Garay ${ }^{1}$; Rocío Martínez Muñoz ${ }^{1}$; Santiago Llorente Viñas²; Juan A. Fernández Hernández $^{3}$; Guillermo A. Gómez Gómez ${ }^{1}$

${ }^{1}$ Servicio de Urología, Hospital Clínico Universitario Virgen de la Arrixaca, Murcia, Spain; ${ }^{2}$ Servicio de Nefrología, Hospital Clínico Universitario de la Arrixaca, Murcia, Spain; ${ }^{3}$ Servicio de Cirugía General y del Aparato Digestivo, Hospital Clínico Universitario Virgen de la Arrixaca, Murcia, Spain

Cite as: Vidal Crespo N, López Cubillana P, López González PA, et al. Simultaneous pancreas-kidney transplantation: Early complications and long-term outcomes - a singlecentre experience. Can Urol Assoc J 2022 February 28; Epub ahead of print. http://dx.doi.org/10.5489/cuaj.7635

Published online February 28, 2022

Corresponding author: Dr. Natalia Vidal Crespo, Department of Urology, Hospital Clínico Universitario Virgen de la Arrixaca, Murcia, 30120, Spain; natalia.vi.cre@gmail.com

$* * *$

\section{Abstract}

Introduction: This study aimed to assess the prevalence and severity of complications after simultaneous pancreas-kidney transplantation (SPKT) and to evaluate its influence on both grafts' long-term results.

Methods: This was an observational, retrospective study including 39 consecutive SPKT cases from 2000-2018. Complications were classified into kidney-related and pancreasrelated. The severity of complications was assessed using the modified Clavien-Dindo scale. Kaplan-Meier curve analysis and log-rank tests were used. Cox regression was performed for the multivariate analysis.

Results: All 39 recipients had long-term type I diabetes. Twenty-one (53.8\%) patients suffered a Clavien-Dindo $\geq$ IIIa complication. Most complications were pancreas-related, with $17(43.6 \%)$ patients suffering from one. Kidney-related major complications were seen in 11 (28.2\%) patients. Patient survival at one, five, and 15 years was $89.7 \%, 87.1 \%$, and $83.9 \%$, respectively; kidney survival was $87.1 \%, 81.4 \%$, and $73.6 \%$, respectively; and pancreas survival was $76.9 \%, 71.3 \%$, and $72 \%$, respectively. Pancreas graft survival was influenced by the presence of major postoperative complications; patients and kidney graft survival were not. 
Conclusions: Complications after SPKT influence pancreas graft survival. Despite the high rate of complications, our results suggest that patients' and kidney graft survival may not be affected by complications.

\section{Introduction}

Patients with end stage renal disease (ESRD) due to type I diabetes mellitus (DM) have a very poor prognosis without a kidney transplantation (1). Simultaneous pancreas-kidney transplantation (SPKT) is the gold standard for these patients (2). Pancreas transplantation is the only therapy that restores normal glucose metabolism in these patients. SPKT not only improves renal disease outcomes, but also other diabetes-related complications such as vascular and neurological complications (3). SPKT can also be performed in selected patients with type $2 \mathrm{DM}$ with similar results to type 1 patients (4), although the 2020 KDIGO guideline only recommended it for type $1 \mathrm{DM}$, with no suggestions for type $2 \mathrm{DM}$ (5). SPKT has an extremely high rate of surgical complications and surgical-related mortality (612). Although there is a trend towards lower complications rates after SPKT (6), most series report relaparotomy rates that vary from $23 \%$ (7) to a $57 \%$ (6). Most of these complications are related to the pancreas. In fact, pancreas transplantation has the highest rate of complications among all the solid organ transplants (8). These complications may have an impact on graft long-term outcomes. It seems logical to think that graft thrombosis or extensive bleeding that needs to be evacuated in an operating room, sometimes with hemodynamic instability, will have an impact on graft outcomes. In fact, thrombosis is commonly managed with graft nephrectomy or pancreatectomy. Some studies describe the negative influence of these complications on pancreas graft long-term outcomes (7-11). However, its influence on kidney graft survival remains unclear, with inconsistent results from published studies (7-12).

The aim of our study was to evaluate the influence of postoperative complications on the long-term survival rates of both grafts and patients.

\section{Methods}

This was an observational retrospective study including all patients who underwent a SPKT in our centre between January 2000 and December 2018.

The surgical technique was identical in all patients. Pancreas transplantation was performed by two general surgeons and kidney transplantation was performed by three different urologists. All pancreases were transplanted into the right iliac fossa. Vascular anastomosis was performed using the common iliac artery and vein, and exocrine drainage was performed by anastomosing the graft's duodenum to the recipient's ileum. Kidney grafts were placed into the left iliac fossa with a second incision. We used the external iliac artery and vein for vascular anastomosis. Ureterocystoneostomy was performed by the Lich-Gregoir technique, using a ureteral stent. Antibiotic prophylaxis was given before anaesthetic induction, generally with amoxicillin/clavulanic acid. The immunosuppression protocol was the same for all patients, consisting of basiliximab induction followed by maintenance with 
tacrolimus, mycophenolate mofetil and prednisone. Thymoglobulin induction is reserved in our centre for hyperimmunised patients. All patients received thromboprophylaxis with lowmolecular-weight heparin, starting 12 hours after the surgery. During the first 24 hours, a CT scan or a Doppler ultrasound was performed in order to rule out early complications, particularly vascular complications.

Complications during the first 90 days after the procedure were registered and divided into kidney and pancreas-related complications. Kidney-related complications included delayed graft function (DGF), graft rejection, arterial or venous thrombosis, arterial stenosis, bleeding, ureteral stenosis, urinary fistula, lymphocele, infectious complications and wound dehiscence. Pancreas-related complications included delayed endocrine graft function, graft rejection, arterial or venous thrombosis, intestinal fistula, bleeding, infectious complications and wound dehiscence. Kidney DGF was defined as the absence of improvement in kidney function during the first week after transplantation. Delayed endocrine graft function was defined as the need for insulin therapy with at least half the dosage needed before transplantation, during the first week after transplantation. Severity of complications was classified according to the modified Clavien-Dindo scale $(13,14)$. For the analysis, we divided complications inro minor (Clavien I-II) and major (Clavien $\geq$ IIIa) complications. When a patient developed more than one complication, the higher-grade complication was taken into account.

For graft survival analysis, the moment of kidney graft loss was defined as the return to dialysis, and pancreas graft failure as returning to insulin requirements as previous to the transplantation. Graft survival was censored for patient death with a functioning graft, and patients with no record of death or graft failure were censored at the date of last follow-up. Statistical analysis was performed using IBM SPSS Statistics 23. Quantitative variables were compared using Student's t-test. For the comparison of qualitative variables, the chi-squared test was used. Survival analysis was performed using the Kaplan-Meier method and log-rank test. Cox proportional hazard models were used for multivariate analysis.

\section{Results}

A total of 39 patients underwent a SPKT in our centre during the time examined. The mean age of the recipients was $35.91 \pm 5.96$ years. Twenty-two $(56.4 \%)$ of them were male. All recipients had long-term type I diabetes, with a mean of $23.54 \pm 5.66$ years from diagnosis. Ten $(25.6 \%)$ of the patients were in the pre-emptive stage, and the rest of them were on substitute treatment, either haemodialysis $(56.4 \%)$ or peritoneal dialysis (17.9\%). All kidneys and pancreas grafts came from brain-dead donors. No donors with expanded criteria were used. The most common cause of death in donors was traumatic brain injury. The mean donor age was 27.67 \pm 9.57 SD years. Median pancreas cold ischemia time was $4 \pm 2.12$ SD hours, although these data were missing for most of the patients (only 10 available). Median kidney cold ischemia time was $8 \pm 3.01$ SD hours. All donor and recipient characteristics can be seen in Table 1.

During the first three months, 21 patients $(53.8 \%)$ suffered from a Clavien-Dindo $\geq$ IIIa complication. The rate of Clavien-Dindo $\geq$ IIIa complications was $43.6 \%$ (17) for pancreasrelated complications and $28.2 \%$ (11) for kidney-related complications. The most frequent 
complication for both grafts were infectious complications, most of them minor, with only one of these requiring surgical treatment. The most severe complications were bleeding, intestinal fistula and vascular thrombosis. All vascular thromboses led to graft loss. There were four transplant-related deaths, three of them secondary to pancreas complications, and one kidney-related. The type of complications, frequencies, and classifications following the modified Clavien-Dindo scale can be found in Table 2.

After the first three months, four patients underwent a relaparotomy for ureteral stricture. No other late transplant-related complications were registered.

Mean follow-up was $96.54 \pm 78.94$ months. Patient survival rates at 1,5 and 15 years were $89.7 \%, 87.1 \%$ and $83.9 \%$; kidney survival rates were $87.1 \%, 81.4 \%$ and $73.3 \%$; pancreas survival rates were $79.9 \%, 71.3 \%$ and $72 \%$, respectively. Patients and kidney graft survival rates were not significantly affected in those who suffered a major complication (Clavien-Dindo $\geq \mathrm{IIIa}$ ), but there was an influence of major complications on the pancreas outcomes. Pancreas survival rates at 1,5 and 15 years were $93.8 \%, 93.8 \%$ and $81.3 \%$ for patients who did not require a relaparotomy, and $57.1 \%, 52.4 \%$ and $45.8 \%$ for those who did $(\mathrm{p}=0.009)$. Kidney graft survival rates were $93.8 \%, 87.5 \%$ and $79.5 \%$; and $76.2 \%, 76.2 \%$ and $68.6 \%$, respectively $(\mathrm{p}=0.873$ ). Patient survival rates for those without a major complication were $93.8 \%, 93.8 \%$ and $93.8 \%$; these rates were $81.0 \%, 76.2 \%$ and $76.2 \%$ for patients who suffered from a Clavien-Dindo $\geq$ IIIa complication $(\mathrm{p}=0.099)$ (Fig. 1).

Regarding kidney-related complications, the presence of a Clavien-Dindo $\geq$ IIIa kidney-related complication showed no influence on patient survival $(\mathrm{p}=0.676)$, pancreas graft survival ( $\mathrm{p}=0.513$ ), or kidney graft survival ( $\mathrm{p}=0.837$ ) (Fig. 2$)$.

Patients who suffered a Clavien-Dindo $\geq$ IIIa pancreas-related complication showed significantly decreased pancreas graft survival $(\mathrm{p}=0.016)$, while there were no significant differences in kidney graft $(\mathrm{p}=0.730)$ and patients $(\mathrm{p}=0.196)$ survival (Fig. 3).

No individual complications or complications sorted by Clavien-Dindo grade revealed a statistically significant influence on survival rates in the multivariate analysis. Although there was a tendency towards worse pancreas survival in those patients who presented pancreatic major complications, these results were not significant [HR 2.42 (95\%CI:0.837.01), $\mathrm{p}=0.1]$.

\section{Discussion}

Complications after SPKT are an important concern, as the relaparotomy rate after the procedure is very high (15). Patients with chronic kidney failure due to type I diabetes do not have a good prognosis without some kind of transplantation, and SPKT is the gold standard in these patients (16).

An initial reduction in patient survival during the first three months compared to patients on the waiting list has been reported. After that, the relation reverses and one-year patient survival after SPKT is better than those on the waiting list (17). This initial decrease in survival is probably due to perioperative complications. Despite these, no study has shown a decrease in long-term patient survival rates for those patients who present major complications (7-11). 
The majority of postoperative complications that require surgical treatment in the SPKT population are pancreas-related $(8,18,19)$, which is consistent with our findings, as $28.2 \%$ of our patients suffered from a kidney-related major complication, whilst the rate was $43.6 \%$ for pancreas-related.

Some donor, recipient and transplant characteristics, such as donor age, cold ischaemia time and time on dialysis treatment have demonstrated an influence on the incidence of surgical complications $(18,20-22)$. Patient selection becomes essential to decrease complications rates. For patients with a short life expectancy, the risk of complications does not outweigh the potential benefit (19). In our series, major complications after SPKT did not affect patient survival rates, although there was a tendency towards significance in those patients who suffered from any kind of major complication $(\mathrm{p}=0.099)$. No other previous study showed decreased patient survival in patients who required a relaparotomy (7-11). Postoperative complications after SPKT have been shown in most previous studies to have a negative influence on pancreas graft survival rates (7-10). These results are consistent with ours, as pancreas survival was influenced by the presence of surgical complications $(\mathrm{p}=0.009)$, and specifically by its pancreas complications $(\mathrm{p}=0.016)$. Kidney-related complications do not seem to influence pancreas graft survival $(\mathrm{p}=0.513)$. There were eight (20.5\%) pancreas graft losses secondary to postoperative complications, five $(62.5 \%)$ of them due to vascular thrombosis, two $(25 \%)$ because of bleeding and the last one $(12.5 \%)$ due to an intestinal fistula.

It is not clear whether pancreas graft loss influences kidney graft survival rates. Hill et al. (23) reported decreased kidney graft survival in patients with early pancreas graft failure (HR 2.08, $\mathrm{p}=0.006$ ). These results were not confirmed by Das et al. (11), as neither kidney graft survival nor patient survival were influenced by pancreas graft loss. Similarly, the influence that major complications may have on kidney graft survival is not clearly established, with contradictory results in scientific reports. Banga et al. (7) found that patients with major complications during the first three months had decreased five-year pancreas survival ( $74 \%$ vs. $82 \%, \mathrm{p}=0.027)$, but no differences were found in kidney survival ( $82 \%$ vs. $83 \% \mathrm{p}=0.412$ ). On the other hand, Campos-Hernandez et al. (12) found decreased five-year kidney graft survival among patients who had Clavien-Dindo $\geq$ IIIb complications $(81.8 \%$ vs. 97.3\%, $\mathrm{p}=0.001$ ). Similar results were found by Manrique et al. (9) and Steurer et al. (10). Neither of these studies separated pancreas-related from kidney-related complications. In our series, patients who presented a surgical complication (either pancreas- or kidney-related, or both of them) did not have a decreased kidney graft survival during follow-up. Of all patients who presented a kidney-related major complication during the first three months, one patient died due to massive haemoperitoneum after kidney graft nephrectomy performed for arterial thrombosis. There were no other patients or graft losses in this group.

The main cause of graft loss during the postoperative period was vascular thrombosis, most of them pancreatic. In fact, in our study, all arterial and venous thromboses resulted in graft loss. Although graft thrombosis rates have decreased over time, mainly because of changes to immunosuppressive protocols (10) and technical improvements (19), it is still the most important cause of graft loss. Pancreas grafts seem to be particularly prone to 
thrombosis. It has been postulated that this could be because of an intrinsically low microcirculatory blood flow, which is based on collateral circulation $(24,25)$. Kidney graft thrombosis seems to be related to atherosclerosis of the recipient iliac artery (26). The limitations of the present study include its retrospective nature, the small number of patients and the fact that it was a single-centre study. Also, the period described is long, meaning that although surgical techniques and immunosuppressive prophylaxis have not changed, some perioperative care items not taken into account in this study may have been different. The long period described also means that follow-up periods of the patients are highly variable, as for some patients it was only two years while for others follow-up was as long as 18 years. Despite these limitations, our results are encouraging and show that, although complications after SPKT are common, they may not affect patient and kidney graft survival rates. Further research with prospective data and larger cohorts is needed to confirm these results. 


\section{References}

1. Parving HH, Hommel E. Prognosis in diabetic nephropathy. BMJ. 1989;298(6693):230-3.

2. Freise CE, Narumi S, Stock PG, Melzer JS. Simultaneous pancreas-kidney transplantation: An overview of indications, complications, and outcomes. West J Med. 1999;170(1):11-8.

3. White SA, Shaw JA, Sutherland DE. Pancreas transplantation. Lancet. 2009;373(9677):1808-17.

4. Cao Y, Liu X, Lan X, Ni K, Li L, Fu Y. Simultaneous pancreas and kidney transplantation for end-stage kidney disease patients with type 2 diabetes mellitus: a systematic review and meta-analysis. Langenbecks Arch Surg. 2021; 1-17

5. Chadban SJ, Ahn C, Axelrod DA, Foster BJ, Kasiske BL, Kher V, et al. KDIGO clinical practice guideline on the evaluation and management of candidates for kidney transplantation. Transplantation. 2020;104 (4S1 Suppl 1):S11-103.

6. Michalak G, Czerwiński J, Kwiatkowski A, Danielewicz R, Kosieradzki M, Lisik W, et al. Surgical complications observed in simultaneous pancreas-kidney transplantation: Thirteen years of experience of one center. Transplant Proc. 2002;34(2):661-2.

7. Banga N, Hadjianastassiou VG, Mamode N, Calder F, Olsburgh J, Drage M, et al. Outcome of surgical complications following simultaneous pancreas-kidney transplantation. Nephrol Dial Transplant. 2012;27(4):1658-63.

8. Troppmann C, Gruessner AC, Dunn DL, Sutherland DER, Gruessner RWG. Surgical complications requiring early relaparotomy after pancreas transplantation: A multivariate risk factor and economic impact analysis of the cyclosporine era. Ann Surg. 1998;227(2):255-68.

9. Manrique A, Jiménez C, López RM, Cambra F, Morales JM, Andrés A, et al. Relaparotomy after pancreas transplantation: causes and outcomes. Transplant Proc. 2009;41(6):2472-4.

10. Steurer W, Malaise J, Mark W, Koenigsrainer A, Margreiter R. Spectrum of surgical complications after simultaneous pancreas-kidney transplantation in a prospectively randomized study of two immunosuppressive protocols. Nephrol Dial Transplant. 2005;20(Suppl2):ii54-61.

11. Das DM, Huskey JL, Harbell JW, Heilman RL, Singer AL, Mathur A, et al. Early technical pancreas failure in Simultaneous Pancreas-Kidney Recipients does not impact renal allograft outcomes. Clin Transplant. 2021;35(e14138):1-6.

12. Campos Hernández JP, Gómez Gómez E, Carrasco Valiente J, Márquez López FJ, Ruiz García J, Anglada Curado FJ, et al. Influence of surgical complications on kidney graft survival in recipients of simultaneous pancreas kidney transplantation. Transplant Proc. 2015;47(1):112-6.

13. Dindo D, Demartines N, Clavien PA. Classification of surgical complications: A new proposal with evaluation in a cohort of 6336 patients and results of a survey. Ann Surg. 2004;240(2):205-13.

14. Clavien PA, Barkun J, De Oliveira ML, Vauthey JN, Dindo D, Schulick RD, et al. The Clavien-Dindo classification of surgical complications: Five-year experience. Ann Surg. 2009;250(2):187-96.

15. Troppmann C. Complications after pancreas transplantation. Curr Opin Organ Transplant. 2010;15(1):112-8. 
16. Barlow AD, Saeb-Parsy K, Watson CJE. An analysis of the survival outcomes of simultaneous pancreas and kidney transplantation compared to live donor kidney transplantation in patients with type 1 diabetes: a UK Transplant Registry study. Transpl Int. 2017;30(9):884-92.

17. Mittal S, Gilbert J, Friend PJ. Donors after circulatory death pancreas transplantation. Curr Opin Organ Transplant. 2017;22(4):372-6.

18. Grochowiecki T, Gałązka Z, Madej K, Frunze S, Nazarewski S, Jakimowicz T, et al. Multivariate analysis of complications after simultaneous pancreas and kidney transplantation. Transplant Proc. 2014;46(8):2806-9.

19. Sollinger HW, Odorico JS, Becker YT, D'Alessandro AM, Pirsch JD. One thousand simultaneous pancreas-kidney transplants at a single center with 22-year follow-up. Ann Surg. 2009;250(4):618-29.

20. Sousa MG, Linhares MM, Gonzalez AM, Rangel EB, Melaragno C, Sá JR, et al. Multivariate analysis of risk factors for early loss of pancreas grafts among simultaneous pancreas-kidney transplants. Transplant Proc. 2010;42(2):547-51.

21. Grochowiecki T, Gałązka Z, Frunze S, Nazarewski S, Jakimowicz T, Pa̧zek L, et al. Influence of simultaneous pancreas and preemptive kidney transplantation on severity of postoperative complications. Transplant Proc. 2011;43(8):3102-4.

22. Gurung K, Alejo J, Rogers J, Farney AC, Orlando G, Jay C, et al. Recipient age and outcomes following simultaneous pancreas-kidney transplantation in the new millennium: Single-center experience and review of the literature. Clin Transplant. 2021; 30(e14302):1-13.

23. Hill M, Garcia R, Dunn T, Kandaswamy R, Sutherland DER, Humar A. What happens to the kidney in an SPK transplant when the pancreas fails due to a technical complication? Clin Transplant. 2008;22(4):456-61.

24. Troppmann C, Gruessner AC, Benedetti E, Papalois BE, Dunn DL, Najarian JS, et al. Vascular graft thrombosis after pancreatic transplantation: Univariate and multivariate operative and nonoperative risk factor analysis. J Am Col Surg. 1996; 182(4): 285316.

25. Blundell J, Shahrestani S, Lendzion R, Pleass HJ, Hawthorne WJ. Risk factors for early pancreatic allograft thrombosis following simultaneous pancreas-kidney transplantation: a systematic review. Clin Appl Thromb. 2020;26 (1076029620942589):1-14.

26. Grochowiecki T, Gałązka Z, Madej K, Frunze S, Nazarewski S, Jakimowicz T, et al. Early complications related to the transplanted kidney after simultaneous pancreas and kidney transplantation. Transplant Proc. 2014;46(8):2815-7. 


\section{Figures and Tables}

Figure 1. Infuence of all complications on patients' $(\boldsymbol{A})$ pancreas; $(\boldsymbol{B})$ kidney; $(\boldsymbol{C})$ graft survival rates.
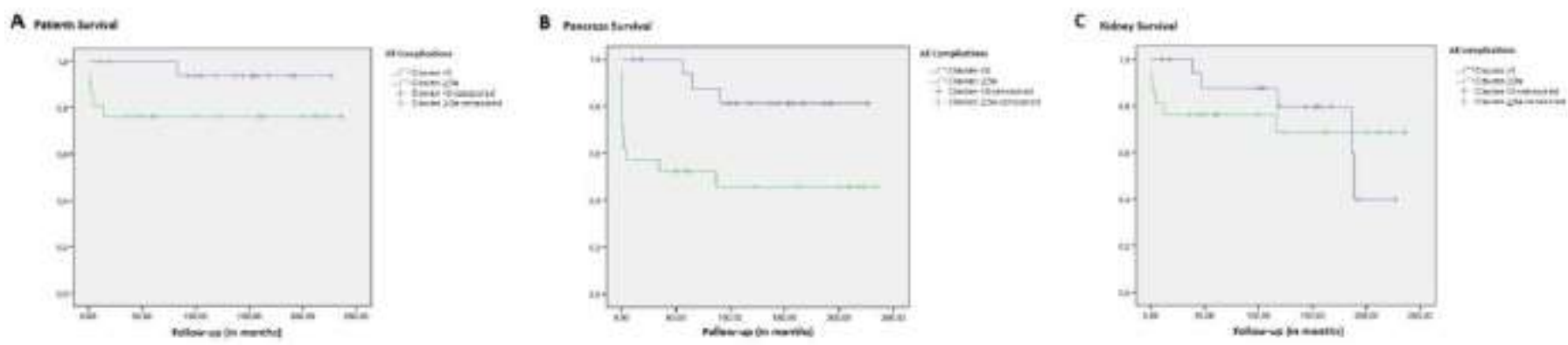

Figure 2. Influence of kidney-related complications on patients' $(\boldsymbol{A})$ pancreas; $(\boldsymbol{B})$ kidney; (C) graft survival rates.
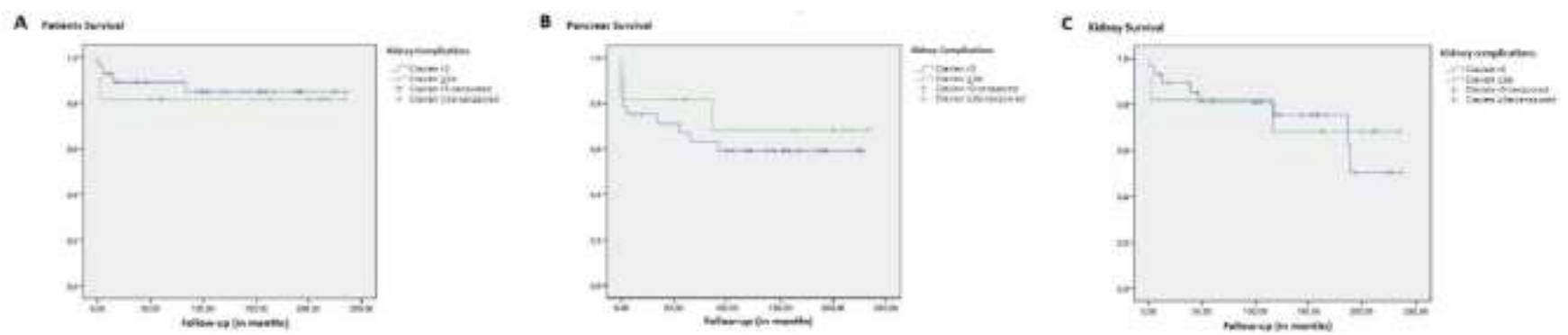

Figure 3. Influence of pancreas-related complications on patients' $(\boldsymbol{A})$ pancreas; $(\boldsymbol{B})$ kidney; (C) graft survival rates.
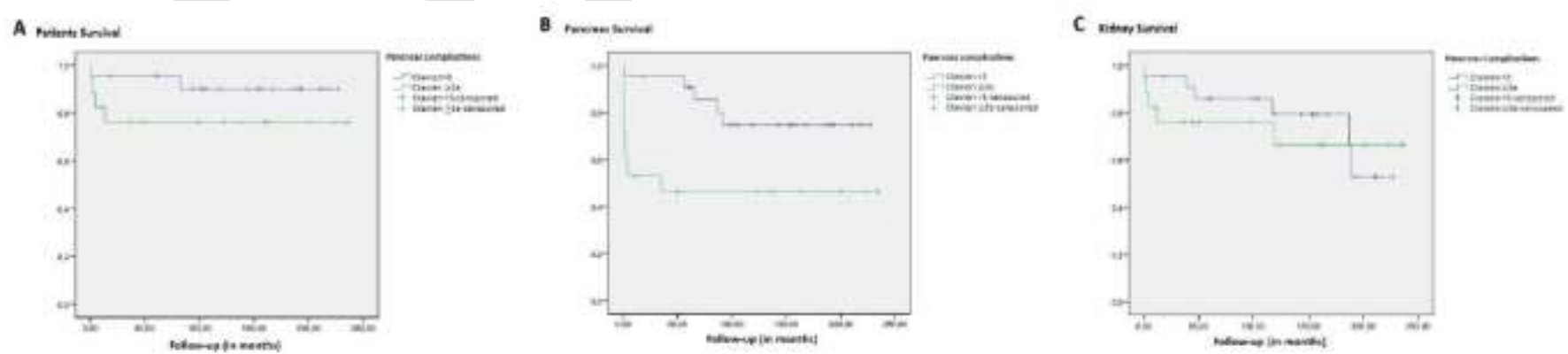


\begin{tabular}{|c|c|c|}
\hline \multicolumn{3}{|c|}{$\begin{array}{l}\text { Table 1. Characteristics of SPKT recipients and donors (expressed by mean } \pm \\
\text { SD, or number [rate]) }\end{array}$} \\
\hline \multicolumn{3}{|c|}{ Donors characteristics } \\
\hline \multicolumn{2}{|l|}{ Age } & $27.67 \pm 9.57$ years \\
\hline \multirow[t]{2}{*}{ Gender } & Female & $14(35.9 \%)$ \\
\hline & Male & $25(64.1 \%)$ \\
\hline \multicolumn{2}{|l|}{ BMI } & $24.48 \pm 3.7$ \\
\hline \multicolumn{2}{|l|}{ Creatinine } & $0.77 \pm 0.27 \mathrm{mg} / \mathrm{dL}$ \\
\hline \multirow[t]{3}{*}{ Cause of death } & Head trauma & $22(56.4 \%)$ \\
\hline & Cerebrovascular/stroke & $13(33.3 \%)$ \\
\hline & Anoxic brain injury & $4(10.3 \%)$ \\
\hline \multicolumn{3}{|c|}{ Recipients characteristics } \\
\hline Age & & $35.91 \pm 5.96$ years \\
\hline \multirow[t]{2}{*}{ Gender } & Female & $17(43.6 \%)$ \\
\hline & Male & $22(56.4 \%)$ \\
\hline BMI & & $22.30 \pm 3.9$ \\
\hline DM time & & $23.54 \pm 5.66$ years \\
\hline Dialysis time & & $15 \pm 27.13$ months \\
\hline \multirow[t]{3}{*}{ Dialysis type } & No dialysis & $10(24.6 \%)$ \\
\hline & Heamodialysis & $22(56.4 \%)$ \\
\hline & Peritoneal dialysis & $7(17.9 \%)$ \\
\hline
\end{tabular}

BMI: body mass index; DM: diabetes mellitus. 


\begin{tabular}{|c|c|c|c|c|c|c|c|c|c|c|c|}
\hline $\begin{array}{c}\text { Type of } \\
\text { complication }\end{array}$ & $\begin{array}{l}\text { Delayed } \\
\text { graft } \\
\text { function }\end{array}$ & $\begin{array}{l}\text { Acute } \\
\text { rejection }\end{array}$ & $\begin{array}{l}\text { Arterial } \\
\text { thrombosis }\end{array}$ & $\begin{array}{l}\text { Venous } \\
\text { thrombosis }\end{array}$ & $\begin{array}{l}\text { Arterial } \\
\text { stenosis }\end{array}$ & $\begin{array}{l}\text { Ureteral } \\
\text { stricture }\end{array}$ & Infection & $\begin{array}{l}\text { Wound } \\
\text { dehiscence }\end{array}$ & Fistula & Bleeding & Lymphocele \\
\hline \multicolumn{12}{|c|}{ Kidney complications } \\
\hline II & 4 & 11 & & & & & 17 & & & 3 & 2 \\
\hline IIIa & & & & & & & +2 & 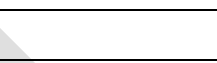 & & & 1 \\
\hline IIIb & & & & & 1 & 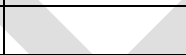 & & 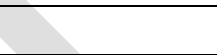 & 3 & 5 & \\
\hline $\mathrm{IVa}$ & & & & & 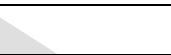 & 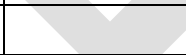 & & 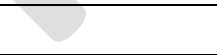 & & & \\
\hline $\mathrm{IVb}$ & & & 1 & & 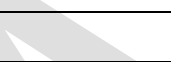 & 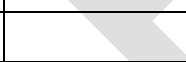 & & & & 1 & \\
\hline Total & $4(10.3 \%)$ & $11(28.2 \%)$ & $1(2.6 \%)$ & 0 & $1(2.6 \%)$ & 0 & \begin{tabular}{|l|}
17 \\
$(43.6 \%)$ \\
\end{tabular} & 0 & $3(7.7 \%)$ & $\begin{array}{l}9 \\
(23.1 \%) \\
\end{array}$ & $3(7.7 \%)$ \\
\hline \multicolumn{12}{|c|}{ Pancreas complications } \\
\hline II & 1 & 5 & & 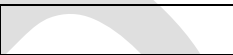 & & 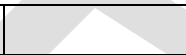 & 12 & & & 8 & \\
\hline IIIa & & & & & & 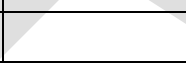 & 1 & 3 & & & \\
\hline IIIb & & & & 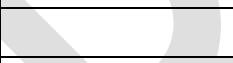 & & & & & 1 & 6 & \\
\hline Iva & & & 3 & 2 & + & 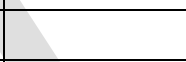 & & & 1 & 2 & \\
\hline Ivb & & & & 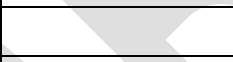 & +2 & 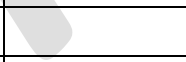 & & & 2 & 1 & \\
\hline Total & $1(2.6 \%)$ & $5(12.8 \%)$ & $3(7.7 \%)$ & $2(5.1 \%)$ & 0 & - & $\begin{array}{l}13 \\
(33.3 \%)\end{array}$ & $3(7.7 \%)$ & $\begin{array}{l}4 \\
(10.3 \%)\end{array}$ & $\begin{array}{l}17 \\
(43.6 \%)\end{array}$ & 0 \\
\hline
\end{tabular}

